\title{
FATIGUE PROPERTIES OF INCLINED CRUCIFORM WELDED JOINTS WITH ARTIFICIAL PITS
}

\author{
Zhi-Yu Jie ${ }^{1,}{ }^{*}$, Wu-Jun Wang ${ }^{1}$, Ping Zhuge ${ }^{1}$, Ya-Dong $\mathrm{Li}^{2}$ and Xing Wei ${ }^{2}$ \\ ${ }^{l}$ Department of Civil Engineering, Ningbo University, Ningbo 315211, China \\ ${ }^{2}$ School of Civil Engineering, Southwest Jiaotong University, Chengdu 610031, China \\ "(Corresponding author: E-mail:jiezhiyu_8@163.com)
}

\section{A B S T RA C T}

Experimental and numerical investigations on the fatigue properties of inclined corroded cruciform joints were conducted in this paper. Two artificial hemispherical notches were used to simulate pitting corrosion damage. Fatigue tests were carried out under uniaxial tensile cyclic loading. The fatigue S-N curves considering different types of corrosion damage were fitted by regression analysis. A relative hot spot stress concentration factor (HSSCF) concept was proposed. The influence of the pit size on the relative HSSCF of the cruciform joints was analyzed based on a numerical analysis. The fatigue notch factor (FNF), which considered the effect of corrosion pits, was used to describe the fatigue strength reduction. The FNF method and the Theory of Critical Distances (TCD) were employed to predict the fatigue life of corroded cruciform joints. It is concluded that pitting corrosion damage reduces the fatigue strength, but specimens without and with smaller corrosion pits exhibited similar fatigue strengths at 2 million cycles. The pit depth and radius are the main parameters affecting the relative HSSCFs, and an equation as a function of the pit depth and radius is obtained. The predicted S-N equations correlate well with the experimental results. The maximum error of the fatigue life calculation results based on these two methods is only $-27.8 \%$. They can be used to predict the fatigue life of corroded cruciform joints.

\section{A R T I C LE H IS T O R Y}

$\begin{array}{ll}\text { Received: } & 27 \text { March } 2020 \\ \text { Revised: } & \text { 2 October } 2020 \\ \text { Accepted: } & \text { 12 October } 2020\end{array}$

\section{K E Y W O R D S}

Inclined cruciform joints;

Corrosion pits:

Hot spot stress concentration

factor;

Fatigue notch factor;

Fatigue life

Copyright $@ 2021$ by The Hong Kong Institute of Steel Construction. All rights reserved.

\section{Introduction}

In recent years, many long-span steel bridges have been built in China. Fatigue and corrosion are two major factors affecting the durability and safety of steel bridges. Environmental corrosion causes a reduction in the thickness, surface roughness, and material strength. For steel bridges subjected to repeated loads and corrosive environments, more severe damage occurs compared to when only repeated loads. Repeated loads and corrosive environments accelerate the fatigue crack initiation and decrease the fatigue life during the service time. Consequently, the investigation of fatigue damage for steel bridges under corrosion conditions is currently a very urgent issue. Some researchers have tried to explore the effect of corrosion damage on the fatigue behavior of engineering materials $[1,2]$. However, there is almost no research on the fatigue properties of corroded welded structures.

A majority of studies on the fatigue assessment of inclined welded structures have been performed. Kim and Kainuma [3] discussed the fatigue behavior of load-carrying cruciform welded joints inclined to repeated loadings and predicted the fatigue life by using the effective stress method. Wang et al. [4] presented an analytical method for the fatigue estimation of inclined welds connecting corrugated plates to flange plates. Khurshid [5] studied the fatigue behavior of butt welds inclined to uniaxial loading from a multiaxial fatigue concept. Susmel et al. [6, 7] used four different stresses and the modified Wöhler curve method to assess the fatigue behavior of inclined welds under uniaxial loading. Generally, the nominal stress, the hot spot stress, the notch stress, and the Theory of Critical Distances (TCD) are applied to the fatigue analyses of welded structures. Compared to the nominal stress and the notch stress, additional computational work is not required for the hot spot stress, and it can be used to model complex welded details that are not included in design codes, such as IIW (the International Institute of Welding) [8], Eurocode3 [9], and DNV (Det Norske Veritas) [10]. Due to the stress fields directly determined by the finite element analysis, the TCD as a useful tool is conveniently used for fatigue estimation [11-16].

Pitting corrosion as serious localized damage causes stress concentrations in a corrosive environment. These corrosion pits are detrimental to the fatigue life, and the effect increase with increasing service time [17-19]. The shapes of corrosion pits are extremely irregular, and they can usually be simplified to a hemisphere or semi-ellipsoid for the convenience of research [20]. Numerous discussions on the relationship between the stress concentration factor (SCF) and the shapes and sizes of corrosion pits are presented. Albrecht [21] pointed out that the SCF had a linear relationship with the pit depth. Cerit [22] concluded that there was a nonlinear relationship between the SCF and pit aspect ratio (the ratio of the pit depth to the pit diameter). However, Kolios [23] found that the SCF showed a linear relation with the aspect ratio. Liu [24] believed that the SCFs depended on the geometrical properties of the corrosion pits. Many scholars reveal that the reduction in the fatigue strength of corrosion members correlates with the corrosive parameters, such as the pit shapes and sizes [25, 26]. Sharifi and Rahgozar [27] gave a function using the average corrosion depth and time as variables to describe the fatigue notch factor (FNF). Ma et al. [28] investigated the effect of the notch depths and aspect ratios on the fatigue life under different stress loadings. Li et al. [29] found that the relative maximum pit depth of corroded bars was related to the fatigue life. Adasooriya et al. [30-33] estimated the fatigue strength of corroded members based on the full-range S-N curve method and the continuum damage mechanics method. However, very few studies address the effect of corrosion pits on the fatigue behavior of welded joints. The fatigue strength curves of welded details that depend on time and a corrosive media have not been discussed in the design guidelines [10]. The same reduction degree of the fatigue strength for different corrosive time is considered in DNV. Further studies are needed to assess the effect of geometrical sizes of the corrosion pits on the fatigue properties of corroded welded joints.

This paper studied the fatigue performance of corroded inclined cruciform joints based on experimental and numerical methods. Two artificial pits in the vicinity of the weld ends were constructed to model the pitting corrosion of cruciform joints. Fatigue tests were carried out on corroded cruciform joints. Fatigue test data were discussed based on fatigue S-N curves by comparison to existing experimental results. A hot spot stress concentration factor (HSSCF) was obtained in the numerical analysis, and a relative HSSCF concept considering the influence of corrosion pits on the stress fields was proposed. The relationship between relative HSSCF and pit size was obtained by the least squares method. Due to the adverse effect of pits, a fatigue notch factor (FNF) was used to describe the reduction in the fatigue strength. The FNF method based on the S-N curve of uncorroded cruciform joints and the TCD were used to assess the fatigue life of corroded cruciform joints. The feasibility and accuracy of the two assessment methods were verified via fatigue test data.

\section{Experimental research}

To simulate the complex stress states of welded joints, load-carrying cruciform joints with $45^{\circ}$ inclined full penetration welds were processed using Q345qC steel plates with a thickness of $16 \mathrm{~mm}$ [34]. These joints were manually welded by $\mathrm{CO}_{2}$ gas shielded welding technology. The chemical composition and mechanical properties are presented in Tables 1 and 2, respectively. The geometrical configuration of a cruciform joint is shown in Fig. 1. 
Table 1

Chemical composition of Q345qC steel (in weight \%)

\begin{tabular}{cccccccccc}
\hline Material & $\mathrm{C}$ & $\mathrm{Si}$ & $\mathrm{Mn}$ & $\mathrm{P}$ & $\mathrm{S}$ & $\mathrm{V}$ & $\mathrm{Cr}$ & $\mathrm{Mo}$ & $\mathrm{Ni}$ \\
\hline Q345qC steel & 0.17 & 0.27 & 1.43 & 0.014 & 0.011 & 0.02 & 0.01 & 0.04 & 0.05 \\
\hline
\end{tabular}

Table 2

Mechanical properties of Q345qC steel

\begin{tabular}{ccccc}
\hline Material & Thickness & Yield strength & Tensile strength & Elongati \\
\hline Q345qC & 16 & 360 & 575 & $28 \%$ \\
\hline
\end{tabular}
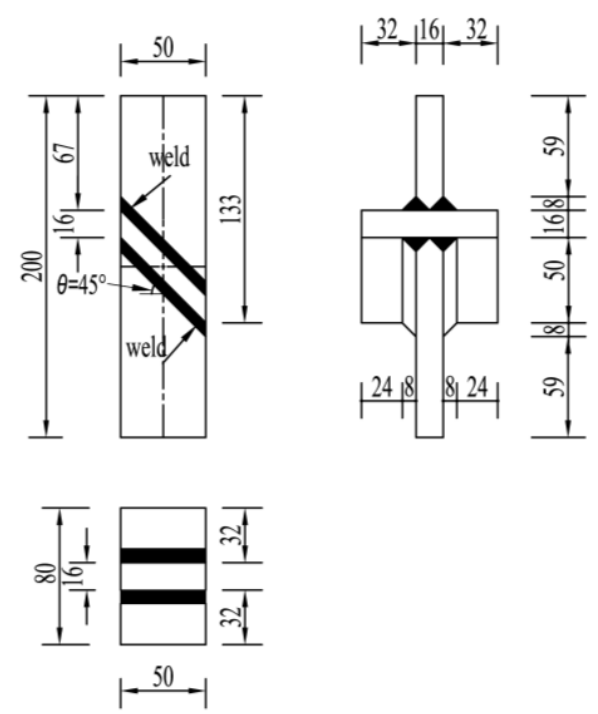

Fig. 1 Configures of the cruciform joints

\subsection{Artificial pits tests}

Studies on metal corrosion in corrosive environments have been carried out for many years. A great number of test data on the corrosion rate of metallic material in different environments can be collected. From these data, it is found that corrosion loss meets the following relationship in a corrosive environment:

$$
D=A t^{B}
$$

where $D$ is the average corrosion depth (mm), $t$ is the number of years, and $A$ and $B$ are the fitted parameters. According to the test data in [35], the parameters for pitting corrosion in a marine atmospheric environment are listed in Table 3. Finally, the mean values of $A$ and $B$ are used to assess the relationship between pit depth and exposure time.

Table 3

Parameters for pitting corrosion

\begin{tabular}{ccc}
\hline No. & $A$ & $B$ \\
\hline 1 & 0.071 & 0.79 \\
2 & 0.207 & 1.12 \\
3 & 0.058 & 0.57 \\
4 & 0.033 & 1.60 \\
5 & 0.047 & 0.63 \\
6 & 0.035 & 0.43 \\
7 & 0.051 & 0.60 \\
8 & 0.025 & 0.54 \\
9 & 0.113 & 0.96 \\
10 & 0.016 & 1.00 \\
11 & 0.090 & 0.92 \\
12 & 0.027 & 0.61 \\
13 & 0.032 & 1.44 \\
\hline
\end{tabular}

\begin{tabular}{ccc}
\hline Mean & 0.062 & 0.86 \\
\hline
\end{tabular}

To investigate the influence of pitting corrosion on the fatigue properties of cruciform joints, the regular pit shapes were taken into account for the convenience of research. Thus, two different hemispherical pits in the welded joints were artificially produced based on Ref. [36]. Two pit depths ( $d=1 \mathrm{~mm}$ and $2 \mathrm{~mm}$ ) and pit widths ( $w=3.5 \mathrm{~mm}$ and $4 \mathrm{~mm}$ ) were considered. The pit radius $R$ maintained a constant value of $2 \mathrm{~mm}$. These corrosion pits were located near the weld ends where fatigue cracks easily initiated. The specific geometrical dimensions of the corrosion pits were detailed in [37]. The distributions of corrosion pits of cruciform joints are shown in Fig. 2.

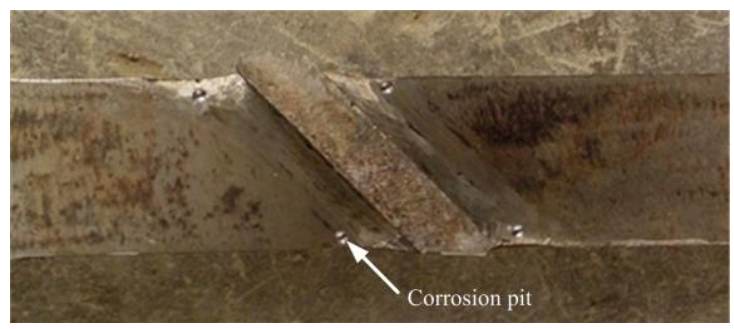

Fig. 2 Cruciform joint with artificial corrosion pits

\subsection{Fatigue tests}

Fatigue tests were carried out under uniaxial constant amplitude repeated loading. A stress ratio of 0.1 and a sinusoidal wave with a loading frequency of approximately $5 \mathrm{~Hz}$ were applied. A total of 27 specimens were designed for three different stress ranges ( $\Delta \sigma=140 \mathrm{MPa}, 160 \mathrm{MPa}$, and $180 \mathrm{MPa}$ ) and pit depths $(d=0 \mathrm{~mm}, 1 \mathrm{~mm}$, and $2 \mathrm{~mm})$. The maximum and minimum loads in one cycle were represented by the symbols $P_{\max }$ and $P_{\min }$, respectively. The corresponding loading conditions are listed in Table 4 , and a fatigue specimen is illustrated in Fig. 3.

Table 4

Loading conditions

\begin{tabular}{|c|c|c|c|c|}
\hline $\begin{array}{l}\text { Types of } \\
\text { corrosion }\end{array}$ & Specimen No. & $\begin{array}{c}\text { Stress range } \\
\text { (MPa) }\end{array}$ & $P_{\min }(\mathrm{kN})$ & $P_{\max }(\mathrm{kN}$ \\
\hline \multirow{3}{*}{$\mathrm{P} 0(d=0, R=0)$} & P0S1 & 140 & 12.4 & 124.4 \\
\hline & P0S2 & 160 & 14.2 & 142.0 \\
\hline & P0S3 & 180 & 16.0 & 160.0 \\
\hline \multirow[t]{3}{*}{$\mathrm{P} 1(d=1 \mathrm{~mm}, R=2$} & P1S1 & 140 & 12.4 & 124.4 \\
\hline & P1S2 & 160 & 14.2 & 142.0 \\
\hline & P1S3 & 180 & 16.0 & 160.0 \\
\hline \multirow[t]{3}{*}{$\mathrm{P} 2(d=2 \mathrm{~mm}, R=2$} & $\mathrm{P} 2 \mathrm{~S} 1$ & 140 & 12.4 & 124.4 \\
\hline & $\mathrm{P} 2 \mathrm{~S} 2$ & 160 & 14.2 & 142.0 \\
\hline & $\mathrm{P} 2 \mathrm{~S} 3$ & 180 & 16.0 & 160.0 \\
\hline
\end{tabular}

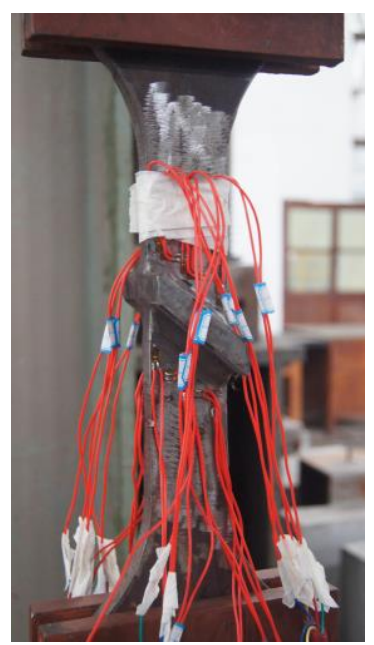

Fig. 3 Fatigue specimen 


\subsection{Results analysis}

The fatigue crack initiation and growth of uncorroded and corroded cruciform joints are shown in Fig 4. The fatigue cracks of all the specimens are generated at the weld toes due to the more obvious stress concentration. Fatigue cracks of uncorroded cruciform joints grow in a straight line, but the fatigue crack propagation path of corroded cruciform joints is a broken line. The fatigue crack first descends and then goes through the pit. The main reason for this behavior may be that the stress and strain fields vary due to the existence of corrosion pits

The fatigue fracture morphology of the cruciform joints is shown in Fig. 5 A semi-elliptical crack propagation trajectory can be observed in the cross section. There are two distinct parts: the smooth part and the rough part. The smooth part contains the fatigue crack initiation and growth stages, and the rough part is the rapid fracture stage.

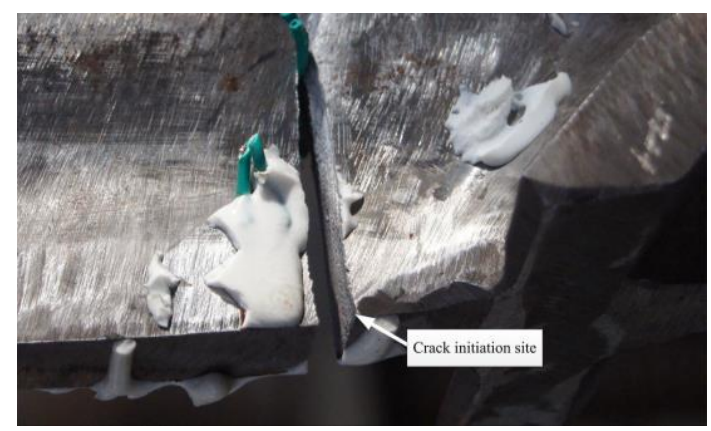

(a) no pit

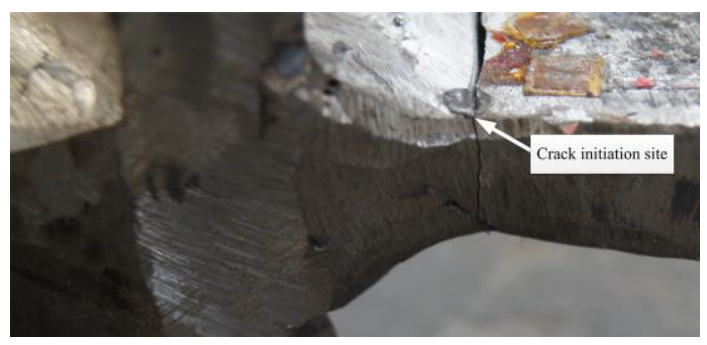

(b) pit 1

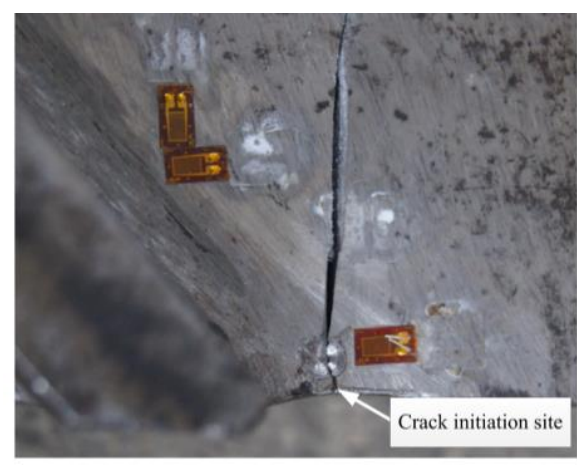

(c) pit 2

Fig. 4 Fatigue crack growth of corroded joints and uncorroded joints

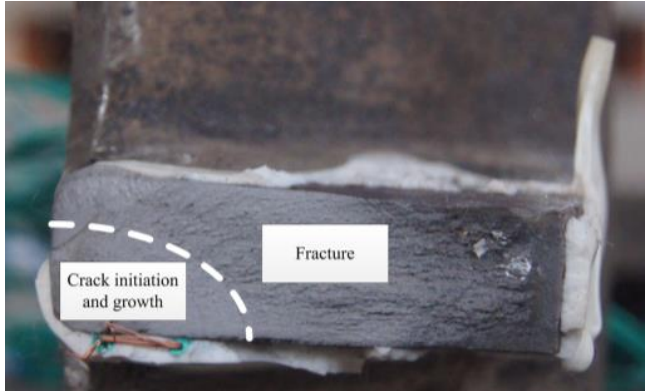

(a) no pit

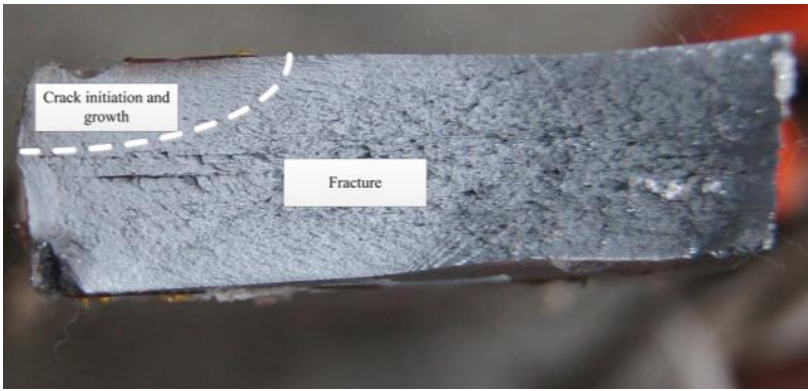

(b) pit 1

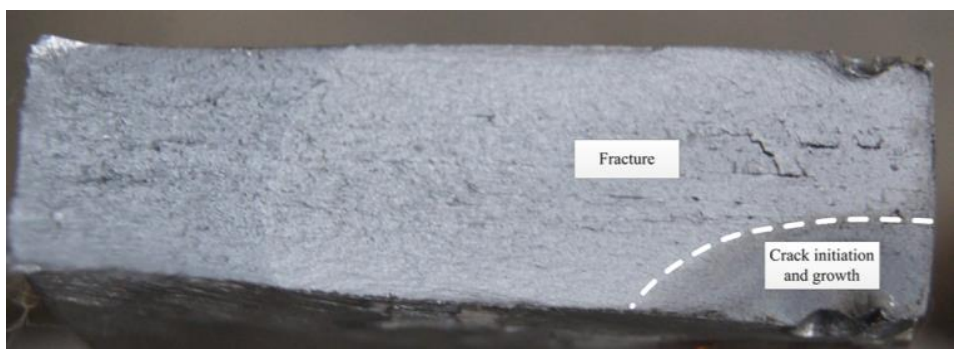

(c) pit 2

Fig. 5 Fatigue fracture morphology of corroded joints and uncorroded joints

The S-N curve is generally used to describe the relationship between stress range $\Delta \sigma$ and fatigue life $N$ based on many experimental results. The equation can be expressed as:
$\Delta \sigma^{m} N=C$ 
where $C$ and $m$ are constants for different metal materials. Eq. (2) is rewritten based on a logarithmic form:

$m \log \Delta \sigma+\log N=\log C$

According to the test results and literature [3], the relationship of stress range vs. mean fatigue life is reported in Fig. 6. The mean and design curves of FAT71 (a stress range of $71 \mathrm{MPa}$ at 2 million cycles with a survival probability of $P_{\mathrm{s}}=97.7 \%$ ) in DNV [10] are also illustrated in Fig. 6.

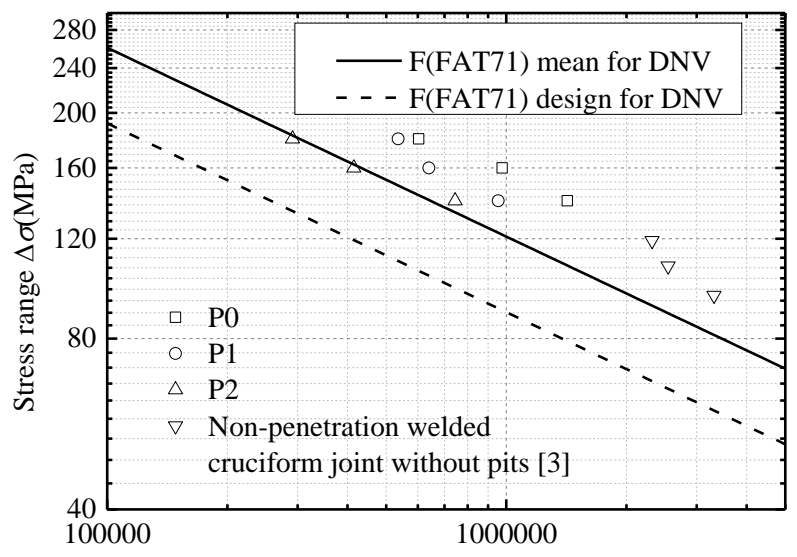

Fatigue life $N($ cycles $)$

Fig. 6 The relationship of stress range vs. mean fatigue life

Regression analysis was employed to obtain the $\log N$ vs. $\log \Delta \sigma$ relationship. An inverse slope of 3 was recommended by the fatigue design specification and chosen in this study [9]. The S-N equations of inclined full penetration fillet welded cruciform joints with $P_{\mathrm{s}}=50 \%$ can be expressed as:

$\log N=12.573-3 \log \Delta \sigma$ for $\mathrm{P} 0$

$\log N=12.438-3 \log \Delta \sigma$ for $\mathrm{P} 1$

$\log N=12.252-3 \log \Delta \sigma$ for $\mathrm{P} 2$

Similarly, the S-N equation for inclined non-penetration fillet welded cruciform joints with no pit can be obtained:

$\log N=12.510-3 \log \Delta \sigma$

The design curves (the mean values-two standard deviation) were determined. The design S-N equations of inclined full penetration fillet welded cruciform joints with $P_{\mathrm{s}}=97.7 \%$ were expressed as:

$\log N=12.198-3 \log \Delta \sigma$ for $\mathrm{P} 0$

$\log N=12.182-3 \log \Delta \sigma$ for P1

$\log N=11.840-3 \log \Delta \sigma$ for $\mathrm{P} 2$

The DNV categories of the welded joints and regression analysis results based on Eq. (8)-(10) are listed in Table 5.
Table 5

DNV categories and regression analysis results

\begin{tabular}{ccccc}
\hline & & & $\Delta \sigma \quad$ at & Corrosion \\
Categories & $\log (C)$ & $m$ & 2 million & condition \\
& & & cycles (MPa) & \\
\hline D & 12.164 & 3 & 90 & No \\
E & 12.010 & 3 & 80 & No \\
F & 11.855 & 3 & 71 & No \\
D & 11.687 & 3 & 62 & Yes \\
E & 11.533 & 3 & 55 & Yes \\
F & 11.378 & 3 & 49 & Yes \\
\hline P0 & 12.198 & 3 & 92 & No \\
P1 & 12.182 & 3 & 91 & Yes \\
P2 & 11.840 & 3 & 70 & Yes \\
\hline
\end{tabular}

It is evident that the fatigue strength of inclined full penetration welded cruciform joints is larger than that of the non-penetration weld. This conclusion is in agreement with the specifications [9]. The inclination weld increases the fatigue strength of uncorroded cruciform joints. It increases by $30 \%$ from $71 \mathrm{MPa}$ to $92 \mathrm{MPa}$ at 2 million cycles. The fatigue strengths of the $\mathrm{P} 0$ and P1 specimens are very close and almost the same as that of the uncorroded category D. The fatigue strengths of categories D, E, and F under corrosion conditions decrease by $31 \%$. However, the fatigue strength of the cruciform joints with pit 2 is reduced by $24 \%$. It is evident that environmental corrosion can reduce the fatigue strength of cruciform joints. The same reduction factor of the fatigue strength used in DNV is very inappropriate. The reduction of the fatigue strength of corroded cruciform joints needs to be quantitatively described. The relation between fatigue strength and geometrical sizes of corrosion pits is needed to conduct an in-depth analysis from a numerical aspect.

\section{Stress concentration analysis}

\subsection{Finite element model}

A 3D finite element model that used quadratic 10-node tetrahedral elements (SOLID92) was developed to simulate the linear elastic stress fields via the commercial software ANSYS. A Young's modulus of $210 \mathrm{GPa}$ and Poisson's ratio of 0.3 were applied to the elastic material properties. A constant stress range of $\Delta \sigma=160$ and a fixed constraint were imposed on both sides of the long steel plates. Fig. 7 plots the FE model of the corroded cruciform joints. The stress distributions of the uncorroded and corroded cruciform joints are plotted in Fig. 8.

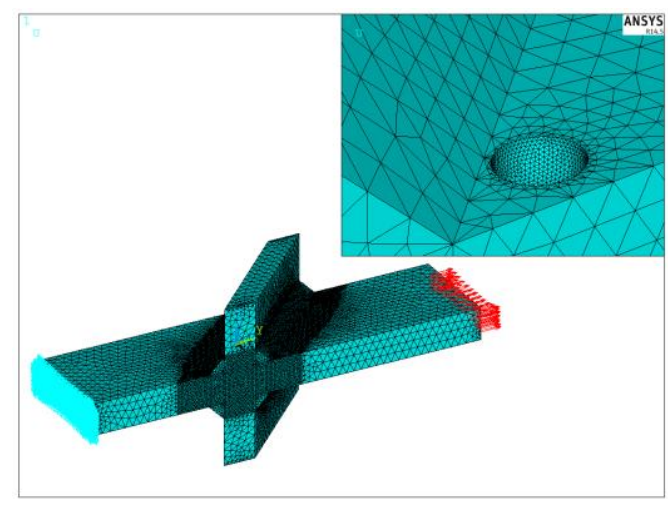

Fig. 7 FE model 


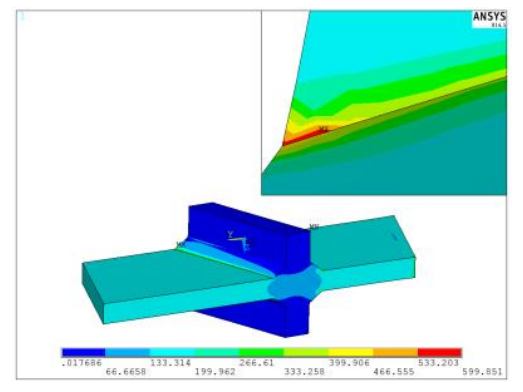

(a) P0

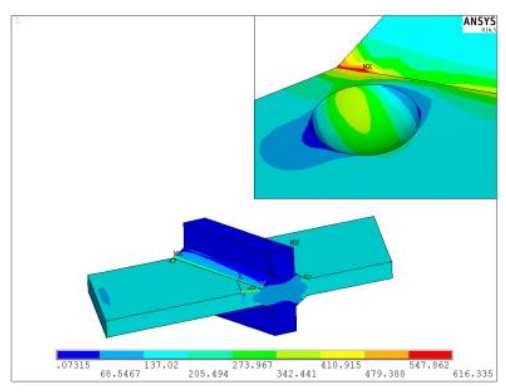

(b) P1

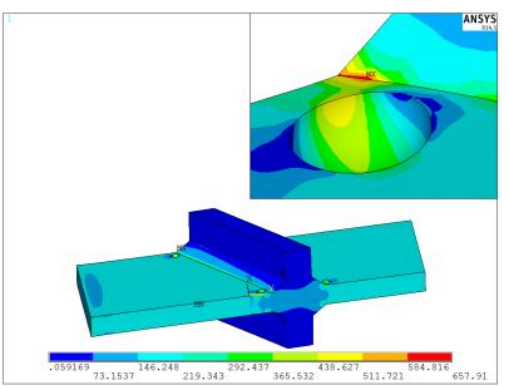

(c) P2

Fig. 8 Stress distributions of the welded joints

The maximum von Mises stress occurs at the weld toes, where fatigue crack are generated. The stress concentrations around the pits are less severe than those of the weld toes. This is consistent with the findings of the fatigue test results. The maximum von Mises stress increases with an increase in the pit depth. The effect of corrosion pits on the stress concentration of cruciform joints is very evident. The relationship between geometrical sizes of corrosion pits and stress concentrations needs to be further studied. However, the mesh size has a significant influence on the maximum stress of the weld toes due to a stress singularity. The hot spot stress can be used to assess the variation in the stress fields for corroded cruciform joints.

\subsection{Hot spot stress concentration factors}

The estimated hot spot stress using the linear extrapolation method can be obtained as follows [8]:

$\sigma_{\mathrm{hs}}=1.67 \sigma_{0.4 \mathrm{t}}-0.67 \sigma_{1.0 \mathrm{t}}$

where $\sigma_{\mathrm{hs}}$ is the hot spot stress of the weld toe, and $\sigma_{0.4 \mathrm{t}}$ and $\sigma_{1.0 \mathrm{t}}$ are the nodal stresses for the two extrapolation points at distances of $0.4 t$ and $1.0 t$ in front of the weld toe (Fig. 9).

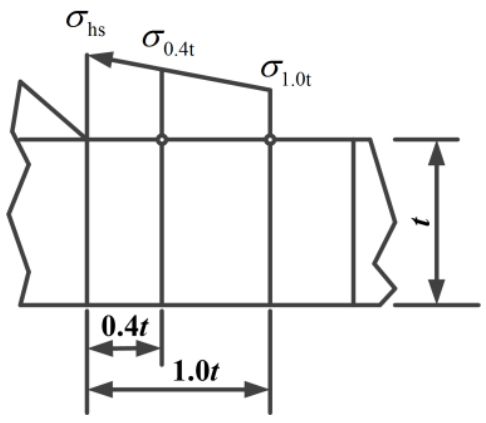

Fig. 9 The definition of hot spot stress

The hot spot stress concentration factor (HSSCF), $K_{\mathrm{hs}}$, is described by the following formula:

$K_{\mathrm{hs}}=\frac{\sigma_{\mathrm{hs}}}{\sigma_{\text {nom }}}$

where $\sigma_{\text {nom }}$ is the nominal stress. To investigate the effect of the pit geometrical size on $K_{\mathrm{hs}}$, different pit depths and radii are considered. A relative $\mathrm{HSSCF}, K_{\mathrm{rhs}}$, is defined as the following:

$K_{\mathrm{rhs}}=\frac{K_{\mathrm{hs}}(d, R)}{K_{\mathrm{hs}}(d=0, R=0)}$

The mesh size had an important influence on the HSSCF. Thus, the mesh gradually increased until convergence. The HSSCFs for different pit depths and radii are shown in Table 6 . Figs. 10-12 plot the relationships between $K_{\text {rhs }}$ and $d, d / w$, and $R$.
Table 6

Size parameters and HSSCFs for different pit depths and radii

\begin{tabular}{|c|c|c|c|c|c|}
\hline No. & $\begin{array}{l}\text { Pit depth } \\
d(\mathrm{~mm})\end{array}$ & $\begin{array}{l}\text { Pit width } \\
w(\mathrm{~mm})\end{array}$ & $d / w$ & $\begin{array}{c}\text { Pit radius } \\
R(\mathrm{~mm})\end{array}$ & $\begin{array}{c}\text { Hot spot stress } \\
\text { concentration } \\
\text { factor } K_{\mathrm{hs}} \\
\end{array}$ \\
\hline 1 & 0 & 0 & - & 0 & 1.083 \\
\hline 2 & 0.25 & 1.323 & 0.189 & 1 & 1.084 \\
\hline 3 & 0.5 & 1.732 & 0.289 & 1 & 1.084 \\
\hline 4 & 0.75 & 1.936 & 0.387 & 1 & 1.090 \\
\hline 5 & 1 & 2 & 0.5 & 1 & 1.102 \\
\hline 6 & 0.375 & 1.984 & 0.189 & 1.5 & 1.083 \\
\hline 7 & 0.5 & 2.236 & 0.224 & 1.5 & 1.084 \\
\hline 8 & 0.75 & 2.598 & 0.289 & 1.5 & 1.117 \\
\hline 9 & 1 & 2.828 & 0.354 & 1.5 & 1.171 \\
\hline 10 & 1.125 & 2.905 & 0.387 & 1.5 & 1.202 \\
\hline 11 & 1.5 & 3 & 0.5 & 1.5 & 1.297 \\
\hline 12 & 0.5 & 2.646 & 0.189 & 2 & 1.089 \\
\hline 13 & 0.75 & 3.122 & 0.240 & 2 & 1.136 \\
\hline 14 & 1 & 3.464 & 0.289 & 2 & 1.209 \\
\hline 15 & 1.5 & 3.873 & 0.387 & 2 & 1.418 \\
\hline 16 & 2 & 4 & 0.5 & 2 & 1.730 \\
\hline
\end{tabular}

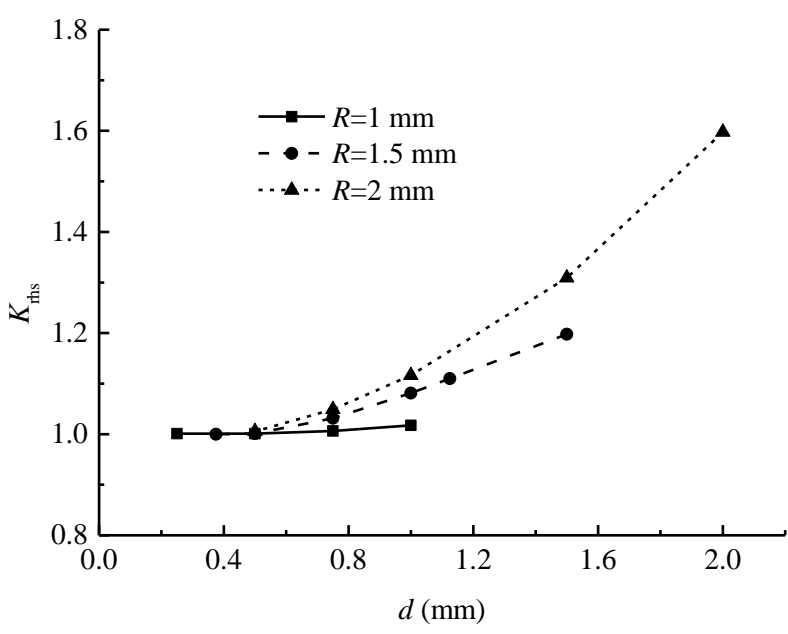

Fig. $10 K_{\text {rhs }}$ versus $d$ for different pit radii 


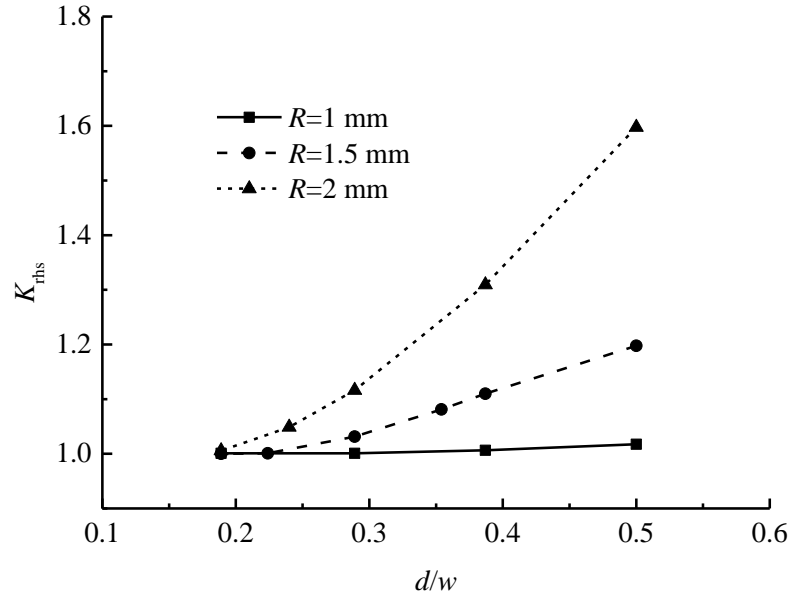

Fig. $11 K_{\text {rhs }}$ versus $d / w$ for different pit radii

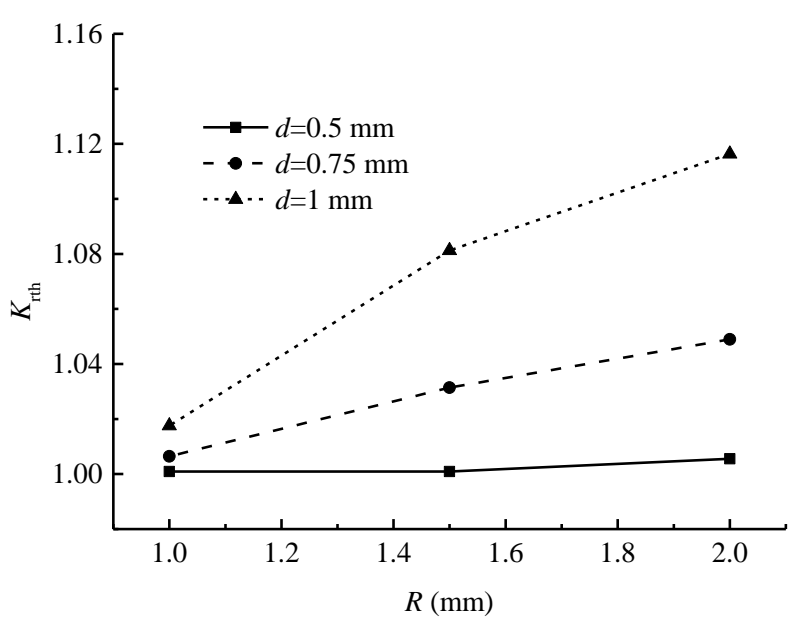

Fig. $12 K_{\text {rhs }}$ versus $R$ for different pit depths

It shows that $K_{\mathrm{rhs}}$ increases with the increase in $d, d / w$, and $R$. The rates of change of $K_{\text {rhs }}$ increase with the increase in $R$ and $d$. When $R=1 \mathrm{~mm}, K_{\text {rhs }}$ is nearly unchanged. However, the relationships between $K_{\text {rhs }}$ and $d$ and $d / w$ vary substantially when $R \geq 1.5 \mathrm{~mm}$. The relative HSSCF should consider the effects of the pit depth and pit radius. The polynomial regression analysis is carried out based on the least squares method. The relative HSSCF equation can be expressed as:

$$
K_{\mathrm{rhs}}=1.085-0.235 d+0.240 d^{2}-0.095 R+0.051 R^{2} \text { for } 0<d / R \leq 1 \text { and } 1 \leq R \leq 2
$$

where the pit depth $d$ and pit radius $R$ have units of millimeters, the correlation coefficient is 0.992 , and the standard deviation is 0.020 . Thus, it is convenient to obtain the relative HSSCF based on the pit depth and pit radius.

\subsection{Fatigue notch factor}

The fatigue notch factor (FNF), $K_{\mathrm{f}}$, is defined by the ratio of the fatigue strength of a plain component $\Delta \sigma_{\mathrm{S}}$ to that of a notched component $\Delta \sigma_{\mathrm{N}}$ under the same conditions, as shown in Fig. 13 . Therefore, $K_{\mathrm{f}}$ can be generally written as:

$K_{\mathrm{f}}=\frac{\Delta \sigma_{\mathrm{S}}}{\Delta \sigma_{\mathrm{N}}}$

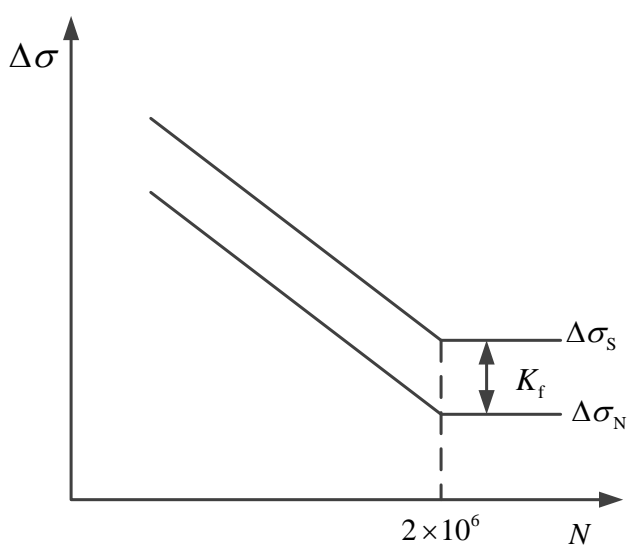

Fig. 13 Definition of the FNF

Based on Eqs. (4)-(6), the FNFs for P1 and P2 are 1.110 and 1.280 at $N=2 \times 10^{6}$ cycles, respectively. According to the computational results of the relative HSSCF, the relationship between $K_{\mathrm{f}}$ and $K_{\text {rhs }}$ is shown in Fig. 14. $K_{\mathrm{f}}$ increases with the increase of $K_{\mathrm{rhs}}$, and there is a linear relationship between them. Therefore, the equation can easily predict the fatigue life of corroded welded joints. The FNF is fitted by the least squares method. The expression of the FNF is written as:

$$
K_{\mathrm{f}}=1+0.486\left(K_{\text {rhs }}-1\right)
$$

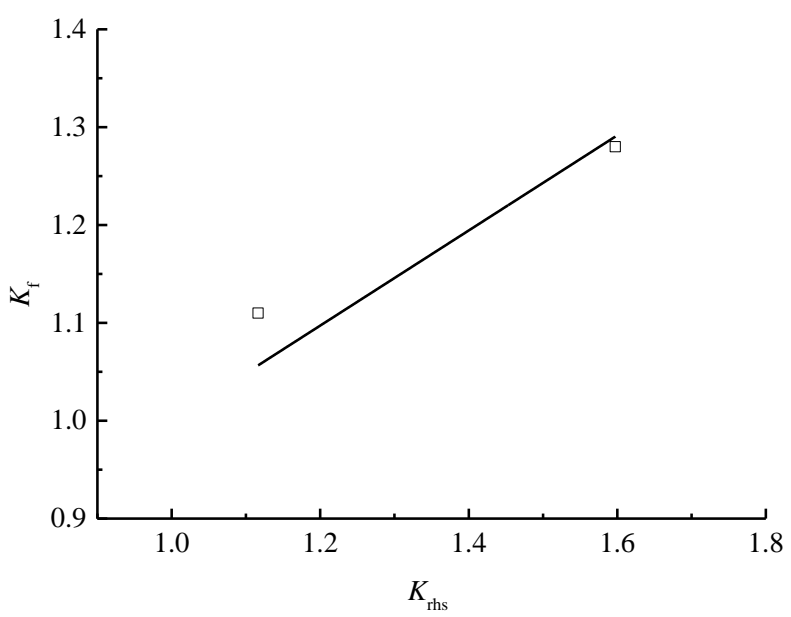

Fig. 14 The relationship between $K_{\mathrm{f}}$ and $K_{\mathrm{rhs}}$

\section{Fatigue life prediction}

\subsection{The FNF method}

The S-N equation considering the FNF can be expressed as:

$\left(K_{\mathrm{f}} \Delta \sigma\right)^{m} N=C$

Eq. (17) can be rewritten as:

$\log N=\log C-m \log \left(K_{\mathrm{f}} \Delta \sigma\right)=\left(\log C-m \log K_{\mathrm{f}}\right)-m \log \Delta \sigma$

The predicted S-N equations of corroded cruciform joints can be expressed as follows based on Eq. (4):

$\log N=12.502-3 \log \Delta \sigma$ for $\mathrm{P} 1$

$\log N=12.242-3 \log \Delta \sigma$ for $\mathrm{P} 2$ 
equations of the corroded cruciform joints are very close to the experimental equations.

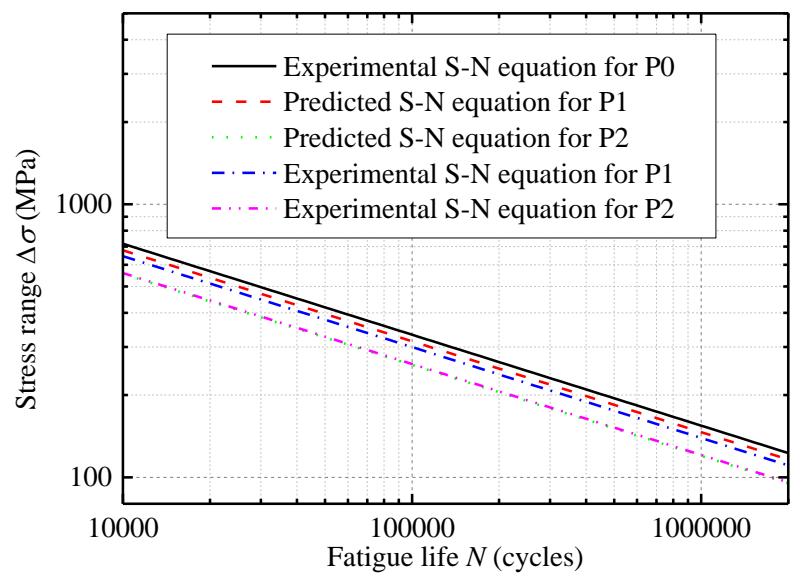

Fig. 15 Experimental and predicted $S-N$ equations

\subsection{Theory of Critical Distances (TCD)}

The TCD has been recently developed for the fatigue assessment of notched members [38]. The TCD can be summarized as four different ways: the point method (PM), the line method (LM), the area method (AM), and the volume method (VM) [39] (Fig. 16). The PM was employed to predict the fatigue life owing to the simple calculation without considering complex post-processing. The distance along the bisector of the weld toes from the potential crack initiation site is equal to $0.5 \mathrm{~mm}$ [7]. In addition, the stress range of the plain specimens at $N=2 \times 10^{6}$ cycles is $256.23 \mathrm{MPa}$ [40]. The accuracy and reliability of the PM in evaluating the fatigue life of inclined cruciform joints with artificial corrosion pits are checked using fatigue test data. A comparison of the fatigue life estimated by the FNF method and the TCD and experimental results is plotted in Fig. 17.
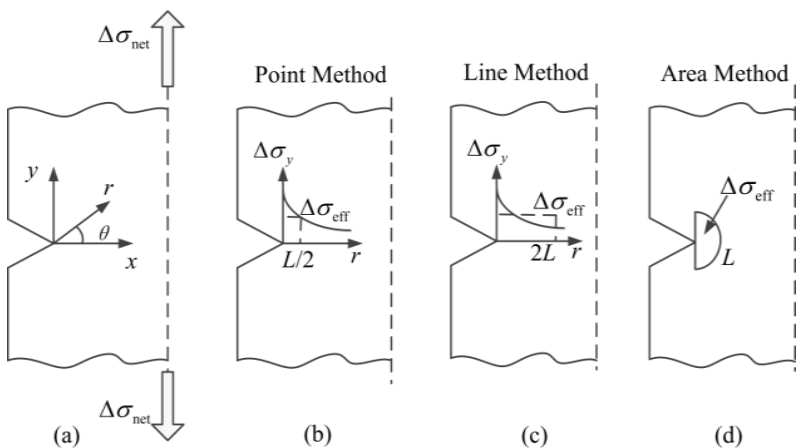

(b)

(c)

(d)

Fig. 16 Local coordinate system (a); the PM (b); the LM (c); and the AM (d)

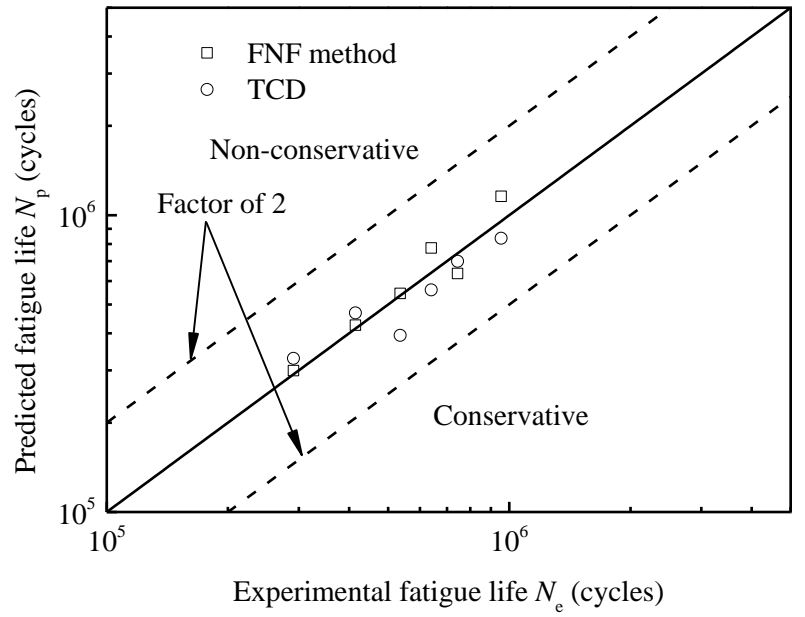

Fig. 17 Fatigue life experimental results versus predicted results
The maximum error of the predicted fatigue life results is only $-27.8 \%$. Fatigue life predicted results agree well with experimental results. Thus, the accuracy of the two methods used to assess the fatigue life is validated. The $\mathrm{S}-\mathrm{N}$ equations of the cruciform joints considering different corrosive time can be estimated by the FNF expression and the S-N equations of uncorroded cruciform joints.

\section{Conclusions}

This paper studied the effect of pitting corrosion damage on the fatigue properties of corroded inclined cruciform welded joints. Based on the above analyses, the following conclusions can be obtained.

(1) The fatigue cracks of all the specimens are generated at weld toes due to the more obvious stress concentration. The fatigue crack propagation paths of uncorroded and corroded cruciform joints are different due to the existence of pits.

(2) The fatigue strength of the inclined full penetration fillet welded cruciform joints is larger than that of the non-penetration weld. The inclination weld increases the fatigue strength of the uncorroded welded joints Fatigue strengths of the P0 and P1 specimens are very close and almost the same as that of the uncorroded category $\mathrm{D}$. The same reduction factor of the fatigue strength for different types of corrosion damage used in DNV is very inappropriate.

(3) The relative HSSCF should consider the effects of the pit depth and pit radius. There is a linear relationship between FNF and relative HSSCF. The predicted S-N equations of the corroded welded joints are very similar to the experimental equations.

(4) The maximum error of the predicted fatigue life results is only $-27.8 \%$. There is good agreement between fatigue life predicted results and experimental results. The accuracy and reliability of these two methods applied to the fatigue life estimation are validated by fatigue test data.

\section{Acknowledgements}

This research is supported by National Natural Science Foundation of China (51708305), Zhejiang Provincial Natural Science Foundation of China (LQ17E080005), Open Foundation of State Key Laboratory Cultivation Base of Mountain Bridge and Tunnel Engineering (CQSLBF-Y17-1), and K. C. Wong Magna Fund in Ningbo University.

\section{References}

[1] Li F. M., Luo X. Y. and Wang K. J. et al., "Pitting Damage Characteristics on Prestressing Steel Strands by Combined Action of Fatigue Load and Chloride Corrosion", Journal of Bridge Engineering, 2017, Vol.22, No.7, pp.4017023.

[2] Larrosa N. O., Akid R. and Ainsworth R. A., "Corrosion-Fatigue: A Review of Damage Tolerance Models", International Materials Reviews, 2018, Vol.63, No.5, pp.283-308.

[3] Kim I. and Kainuma S., "Fatigue Life Assessment of Load-Carrying Fillet-Welded Cruciform Joints Inclined to Uniaxial Cyclic Loading", International Journal of Pressure Vessels and Piping, 2005, Vol.82, No.11, pp.807-813.

[4] Wang Z. Y. and Wang Q. Y., "Fatigue Assessment of Welds Joining Corrugated Steel Webs to Flange Plates", Engineering Structures, 2014, Vol.73, pp.1-12.

[5] Khurshid M., Barsoum Z. and Barsoum I. et al., "The Multiaxial Weld Root Fatigue of But Welded Joints Subjected to Uniaxial Loading", Fatigue \& Fracture of Engineering Materials \& Structures, 2016, Vol.39, No.10, pp.1281-1298.

[6] Susmel L., "Nominal Stresses and Modified Wöhler Curve Method To Perform The Fatigue Assessment of Uniaxially Loaded Inclined Welds", Proceedings of the Institution of Mechanical Engineers, Part C: Journal of Mechanical Engineering Science, 2014, Vol.228, No.16, pp.2871-2880.

[7] Zamzami I. A. and Susmel L., "On the Use of Hot-Spot Stresses, Effective Notch Stresses and the Point Method to Estimate Lifetime of Inclined Welds Subjected to Uniaxial Fatigue Loading", International Journal of Fatigue, 2018, Vol.117, pp.432-449

[8] Hobbacher A., "Recommendations for Fatigue Design of Welded Joints and Components", Welding Research Council, 2009.

[9] Eurocode 3: "Design of Steel Structures Part 1-9: Fatigue", 2005.

[10] Det Norske Veritas, "Fatigue Design of Offshore Steel Structures", 2010.

[11] Righiniotis T. D. and Imam B. M., Chryssanthopoulos M. K., "Fatigue Analysis of Riveted Railway Bridge Connections Using the Theory of Critical Distances", Engineering Structures, 2008, Vol.30, No.10, pp.2707-2715.

[12] Shahri M. M. Sandström R , and Osikowicz W., "Critical Distance Method to Estimate the Fatigue Life Time of Friction Stir Welded Profiles", International Journal of Fatigue, 2012, Vol.37, pp.60-68.

[13] Zhou H., Wen J. and Wang Z. et al., "Fatigue Crack Initiation Prediction of Cope Hole Details in Orthotropic Steel Deck Using the Theory of Critical Distances", Fatigue \& Fracture of Engineering Materials \& Structures, 2016, Vol.39, No.9, pp.1051-1066.

[14] Al Zamzami I. and Susmel L., "On The Accuracy of Nominal, Structural, and Local Stres Based Approaches in Designing Aluminium Welded Joints Against Fatigue", International Journal of Fatigue, 2017, Vol.101, pp.137-158.

[15] Karakas Ö., Zhang G. and Sonsino C. M., "Critical Distance Approach for The Fatigue Strength Assessment of Magnesium Welded Joints in Contrast to Neuber's Effective Stress Method", International Journal of Fatigue, 2018, Vol.112, pp.21-35.

[16] Al Zamzami I., Davison B. and Susmel L., "Nominal and Local Stress Quantities to Design Aluminium-to-Steel Thin Welded Joints against Fatigue", International Journal of Fatigue, 2019, Vol.123, pp.279-295. 
[17] Soape J., "Investigating the Effects of Corrosion on the Fatigue Life of Welded Steel Attachments", Texas A\&M University, College Station, US, 2012.

[18] Yang S., Yang H. and Liu G. et al., "Approach for Fatigue Damage Assessment of Welded Structure Considering Coupling Effect Between Stress and Corrosion", International Journal of Fatigue, 2016, Vol.88, pp.88-95.

[19] Fu Y., Xiong J. J. and Shenoi R. A., "New Models for Depicting Corrosion Fatigue Behaviour and Calendar Life of Metallic Structural Component", Proceedings of the Institution of Mechanical Engineers, Part C: Journal of Mechanical Engineering Science, 2017, Vol.231, No.2, pp.207-222.

[20] Xu S. H., Ren S. B. and Wang Y. D., "Effects of Pitting Corrosion on the Fatigue Behavior of Q235 Steel", Journal of Harbin Institute of Technology (New Series), 2017, Vol.24, No.1, pp.81-90. (in Chinese)

[21] Albrecht P., Shabshab C. F., and Li W. et al., "Remaining Fatigue Strength of Corroded Steel Beams", 1990

[22] Cerit M., Genel K. and Eksi S., "Numerical Investigation on Stress Concentration of Corrosion Pit", Engineering Failure Analysis, 2009, Vol.16, No.7, pp.2467-2472.

[23] Kolios A., Srikanth S. and Salonitis K., "Numerical Simulation of Material Strength Deterioration due to Pitting Corrosion", Procedia CIRP, 2014, Vol.13, pp.230-236.

[24] Liu G., Huang Y. and Zhang Q. et al., "Fatigue Damage Estimation of Welded Joints Considering Mechanochemical Interaction", 36th International Conference on Ocean, Offshore and Arctic Engineering, Trondheim, Norway, 2017.

[25] Bray G. H., Bucci R. J. and Colvin E. L. et al., "Effect Of Prior Corrosion on the S/N Fatigue Performance of Aluminum Sheet Alloys 2024-T3 and 2524-T3", ASTM International, 1997, pp.89-103.

[26] Dicecco S., Altenhof W. and Hu H. et al., "High-Cycle Fatigue of High-Strength Low Alloy Steel Q345 Subjected to Immersion Corrosion for Mining Wheel Applications", Journal of Materials Engineering and Performance, 2017, Vol.26, No.4, pp.1758-1768.

[27] Sharifi Y., Rahgozar R., "Fatigue Notch Factor in Steel Bridges Due to Corrosion", Archives of Civil and Mechanical Engineering, 2009, Vol.9, No.4, pp.75-83.

[28] Ma Y. F., Wang Q. and Guo Z. Z. et al., "Static and Fatigue Behavior Investigation of Artificial Notched Steel Reinforcement", Materials, 2017, Vol.10, No.5, pp.532-545.
[29] Li S. B., Tang H. W. and Gui Q. et al., "Fatigue Behavior of Naturally Corroded Plain Reinforcing Bars", Construction and Building Materials, 2017, Vol.152, pp.933-942.

[30] Adasooriya N. D. and Siriwardane S. C., "Remaining Fatigue Life Estimation of Corroded Bridge Members", Fatigue \& Fracture of Engineering Materials \& Structures, 2014, Vol.37, No.6, pp.603-622.

[31] Adasooriya N. D., Hemmingsen T. and Pavlou D., "Fatigue Strength Degradation of Metals in Corrosive Environments", IOP Conference Series: Materials Science and Engineering, Norway, 2017.

[32] Sun B., "A Continuum Model for Damage Evolution Simulation of The High Strength Bridge Wires due to Corrosion Fatigue", Journal of Constructional Steel Research, 2018, Vol.146, pp.76-83.

[33] Adasooriya N. D., Pavlou D. and Hemmingsen T., "Fatigue Strength Degradation of Corroded Structural Details: a Formula for S-N Curve", Fatigue \& Fracture of Engineering Materials \& Structures, 2020, Vol.43, No.4, pp.721-733.

[34] GB/T 714-2015. "Structural Steel for Bridge", 2015. (in Chinese)

[35] Cao C. N., "Corrosion in Natural Environment of Materials in China", Chemical Industry Press, Beijing, China, 2005. (in Chinese)

[36] Jakubowski M., "Influence of Pitting Corrosion on Fatigue and Corrosion Fatigue of Ship Structures Part I Pitting Corrosion of Ship Structures", Polish Maritime Research, 2013, Vol.21, No.1, pp.62-69.

[37] Jie Z. Y., Li Y. D. and Wei X. et al., "Fatigue Life Prediction of Welded Joints with Artificial Corrosion Pits Based on Continuum Damage Mechanics", Journal of Constructional Steel Research, 2018, Vol.148, pp.542-550.

[38] Susmel L., "Multiaxial Notch Fatigue: from Nominal to Local Stress-Strain Quantities", Woodhead \& CRC, Cambridge, UK, 2009.

[39] Louks R. and Susmel L., "The Linear-Elastic Theory of Critical Distances to Estimate High-Cycle Fatigue Strength of Notched Metallic Materials at Elevated Temperatures", Fatigue \& Fracture of Engineering Materials \& Structures, 2015, Vol.38, No.6, pp.629-640.

[40] Li H., Zhao B. and Zhu H., "Numerical Simulation of Fatigue Performance of Diaphragm of Large-Span Bridge Orthotropic Deck", Complexity, 2018. 